\title{
Software used for diploma thesis at Geoinformatics VSB-TUO
}

\author{
Jan Růžička \\ Institute of Geoinformatics \\ Faculty of Mining and Geology, VSB-TUO \\ E-mail: jan.ruzicka@vsb.cz
}

Keywords: Software, GIS, open source, freeware, commercial, diploma thesis

\begin{abstract}
The paper describes software usage for diploma thesis presented by VSB-TUO students during students conference GISáček. A prepared statistics was build from papers available at web pages of the conference. The prepared statistics is not complete clear view on this area, but I do not have any other simple way how to prepare such statistics.

The statistics was build just from the text of the papers. If a student mentioned any software than it is included in the statistics. Summarized results are presented at the following figures with some general comments, that can be useful.

The statistics is prepared only for years 2000 - 2006. A last year of the conference was not included, because of problems with availability of the proceedings.

Software is categorized to three categories. A category fee contains only software that must be payed. This category includes software that can be obtained by students free of charge, but for firm usage must be payed. A category without fee includes software that can be used free of charge even for firm purposes, but is not available as an open source software. The last category open source includes open source software and in a case of this statistics, all open source software mentioned by students is free of charge as well.
\end{abstract}

\section{GIS and CAD software}

Category GIS and CAD software includes all software that can be directly used for spatial data manipulation. There are not included systems such as MySQL, Oracle, GIMP, Statgraphics that can be used for spatial data manipulation, but they were not used as GIS or CAD software for the thesis.

Complete list of the GIS and CAD software that were mentioned by students follows: ArcIMS, ArcView IMS, MapGuide, JShape, PMS, Deegree, MapServer, ArcInfo (ArcGIS), Surfer Ar- 
cPad, TopoL, ArcSDE, ERDAS Imagine, Infomapa, MapObjects, KOKEŠ, Patch Analyst, ArcInfo (7.x), PC ARC/INFO, FlowMap, ArcView, AutoCAD, Microstation, IRAS-C, GeoMedia, Pathfinder Office, Cadfusion, Kristýna GIS, OCAD, Terra Explorer, GDAL, Thuban, MapWindow, uDIG, OGR, QGIS, gvSIG, GeoTools, PostGIS, GPSsim, OpenMAP, JUMP, JgraphT, Transform, NVIZ, Vis5D+, Trand'ák, FWTools, GRASS.

OGR, GDAL or other libraries were used as an individual software pieces not as a part of MapServer or GRASS software.

\section{GIS and CAD software}

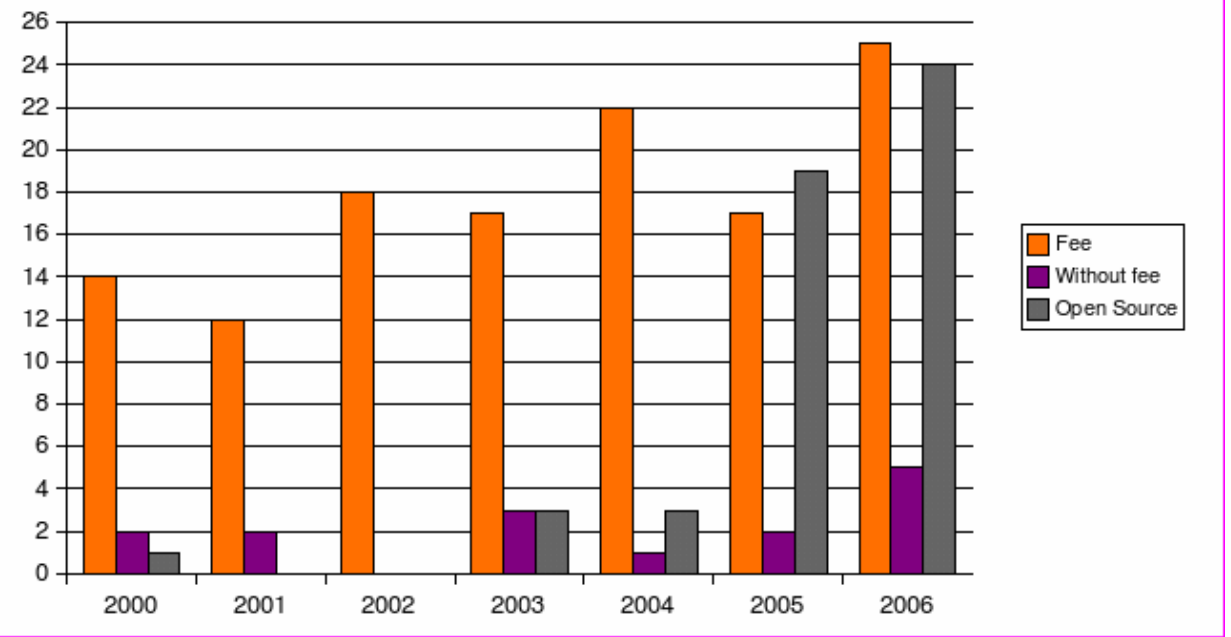

Figure 1: GIS and CAD software

The figure 1 shows number of GIS and CAD software used during 2000 - 2006 period by students. We can see high increase of the number of open source and software without fee in the last two years. To be correct we must mention that for several tasks user in the open source area usually uses not only one software, but a set of software. In the area of commercial software this is not so common. For this purpose you can find figure 4 that shows software used by individual student.

Figure 2 shows number of Web Mapping software used during 2000 - 2006 period. We can see that there was free or open source software used every year when Web Mapping software was used. A complete list of the used web mapping software follows: ArcIMS, ArcView IMS, MapGuide, Jshape, PMS, Deegree, MapServer.

Figure 4 shows how is GIS and CAD software used by individual student. There are three categories of students: students that use only fee software, students that use only free ware software (including open source) and students that use both kind of software.

Very interesting is popularity of ESRI software between students. Although we use different software for teaching during the study, the first one software that is used is ESRI software (ArcView in the past and ArcGIS nowadays). This is described at the figures 5,6 and 7.

Figure 5 shows that other than ESRI commercial software for GIS and CAD is not generally used by our students. Situation will not probably be better in the next years, because our university paid for site licence of the ESRI products. This license will be available for all 
Web Mapping software

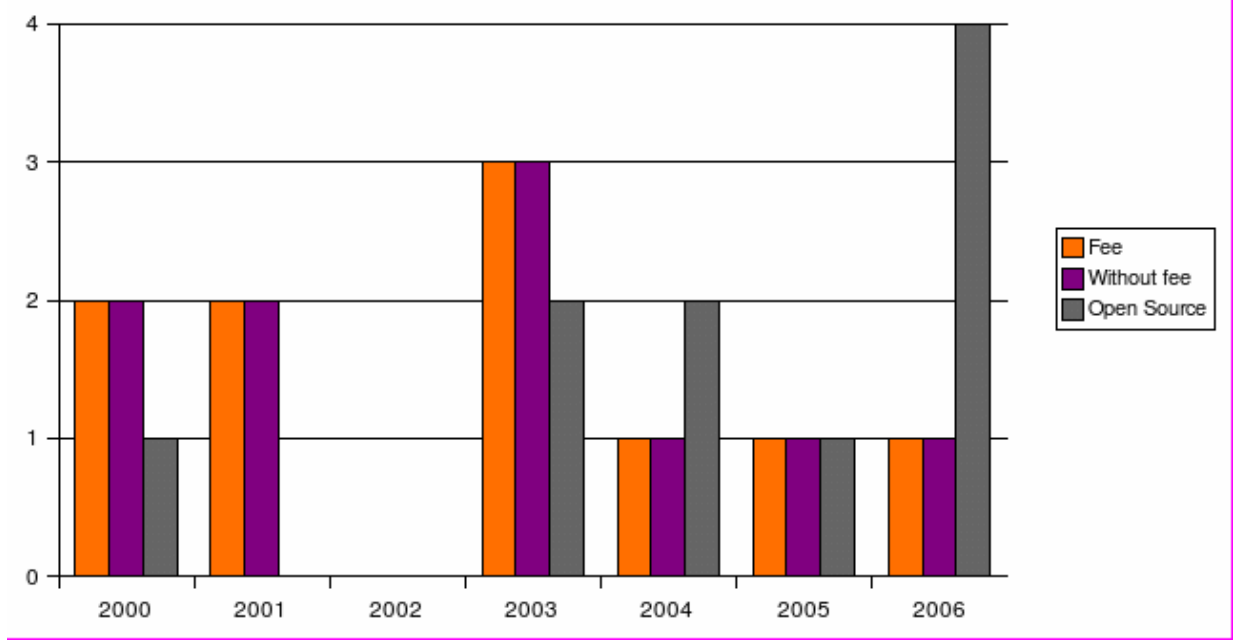

Figure 2: Web Mapping software

GIS and CAD (without WebMapping) software

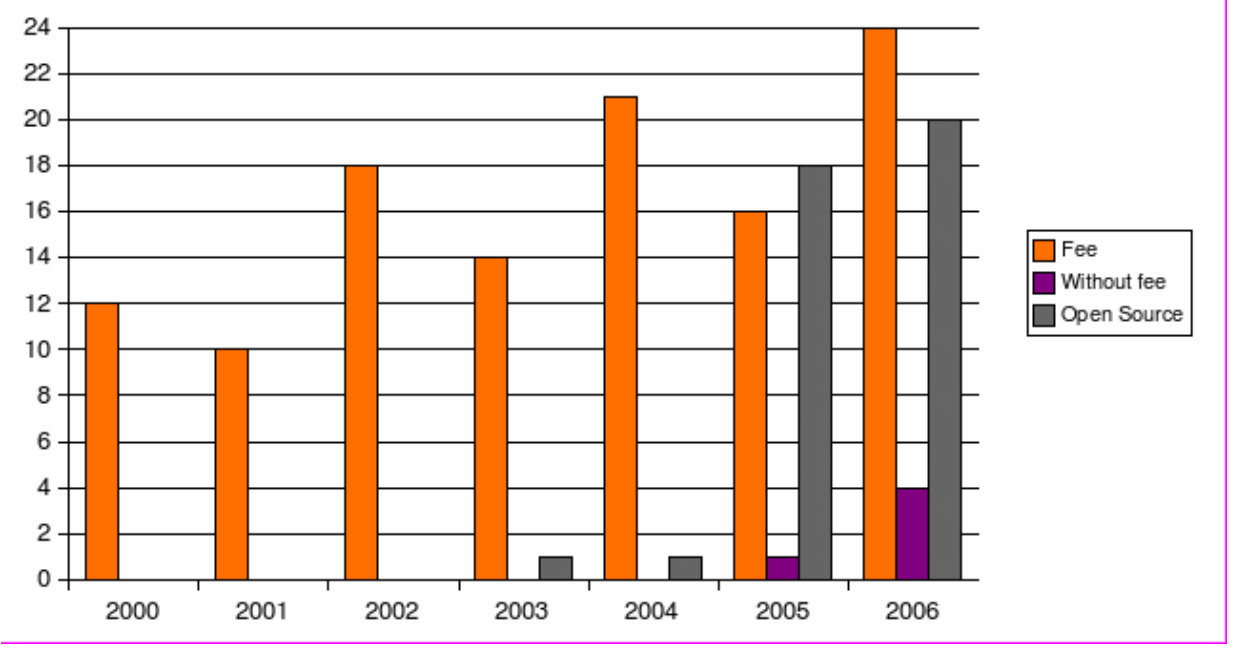

Figure 3: GIS and CAD software without Web Mapping software

students that are connected via VPN to the campus intranet. I feel this as a problem, that can be solved only by other GIS and CAD software vendors action via companies that can prepare diploma thesis for our students.

Figure 6 and 7 shows that our students are usually in face of decision: Use ESRI or open source software. Diploma thesis that are written by our students are usually prepared for some company (commercial, non-commercial). Does it mean that for the practice are only these two options? I believe that not, and that the reason is a structure of our company partners specialization.

Very intersting is usage of individual software during whole period. At figure 8 you can see that more than $40 \%$ are ArcInfo (from ArcGIS edition) and ArcView 3.x, about 38\% is 
GIS and CAD software by individual student

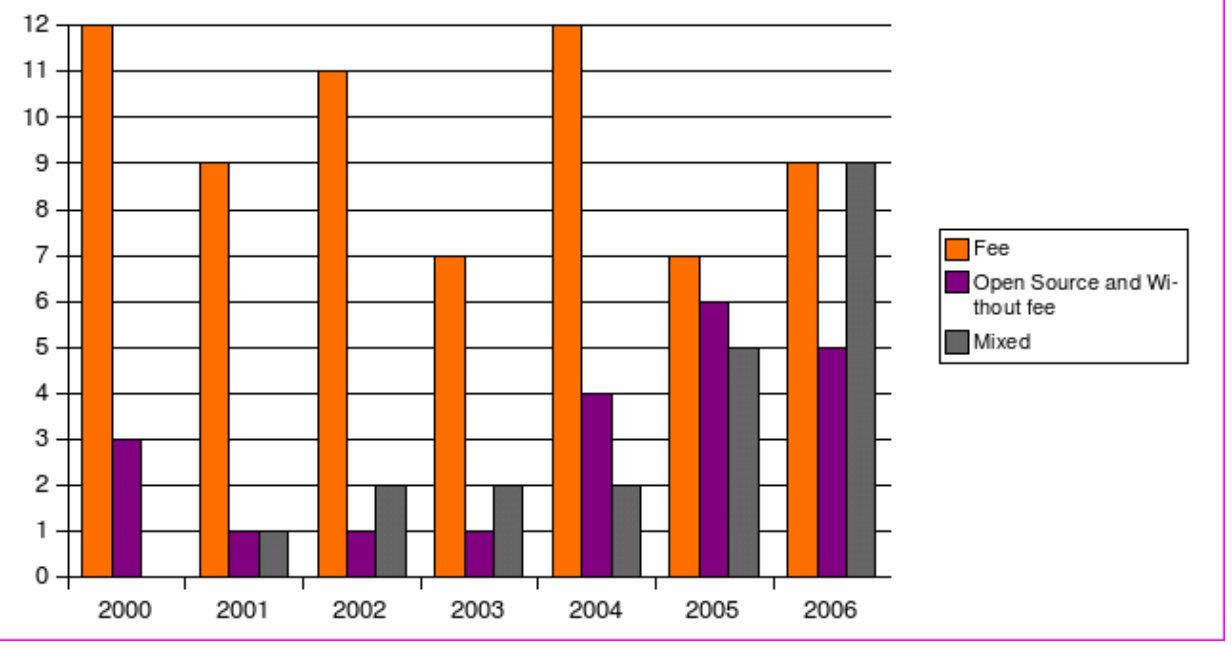

Figure 4: GIS and CAD software by individual student

ESRI and other GIS fee software

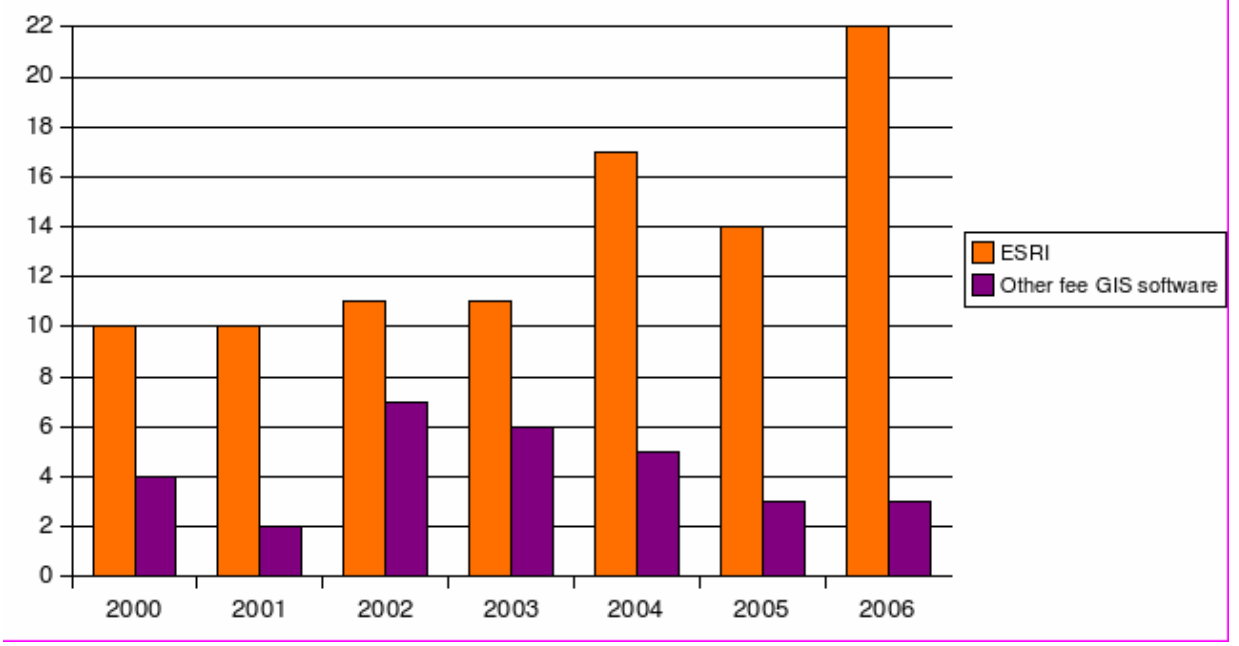

Figure 5: ESRI and other GIS and CAD fee software

distributed between software with usage less than $2 \%$. About $18 \%$ is divided between open source software MapServer, PostGIS, GRASS, JUMP and commercial software MapGuide (before it has been open source), ArcIMS.

You can compare this individual software usage for 2000 - 2006 period with single year 2006 that is described at figure 9. ArcInfo and ArcView are still quite strong, but there is remarkable increase of other open source software. OGR and GDAL in this case were used as an individual software pieces not as a part of MapServer or GRASS software. 
ESRI and GIS open source and without fee software

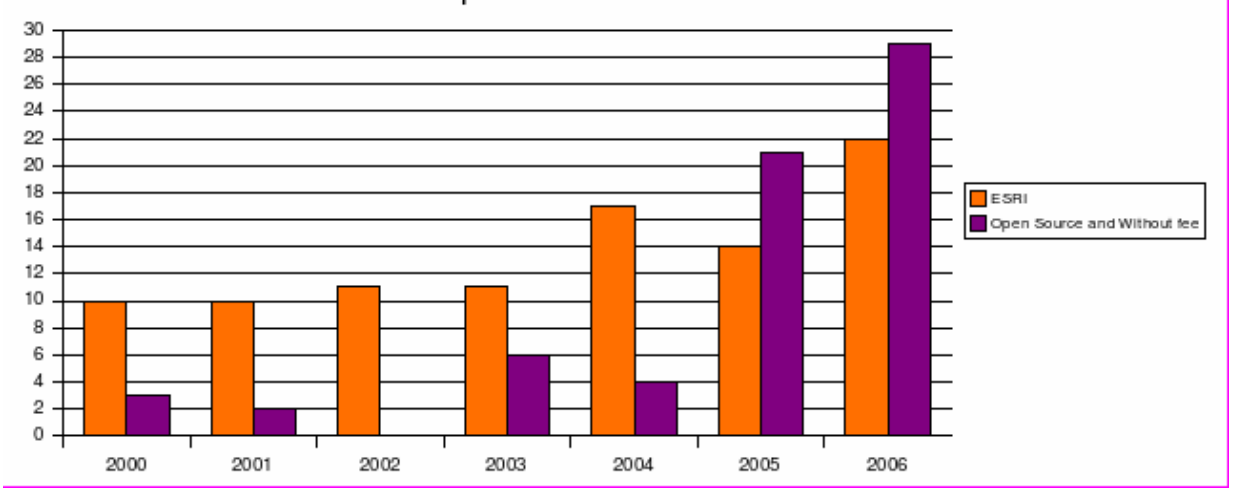

Figure 6: ESRI and other GIS and CAD open source and without fee software

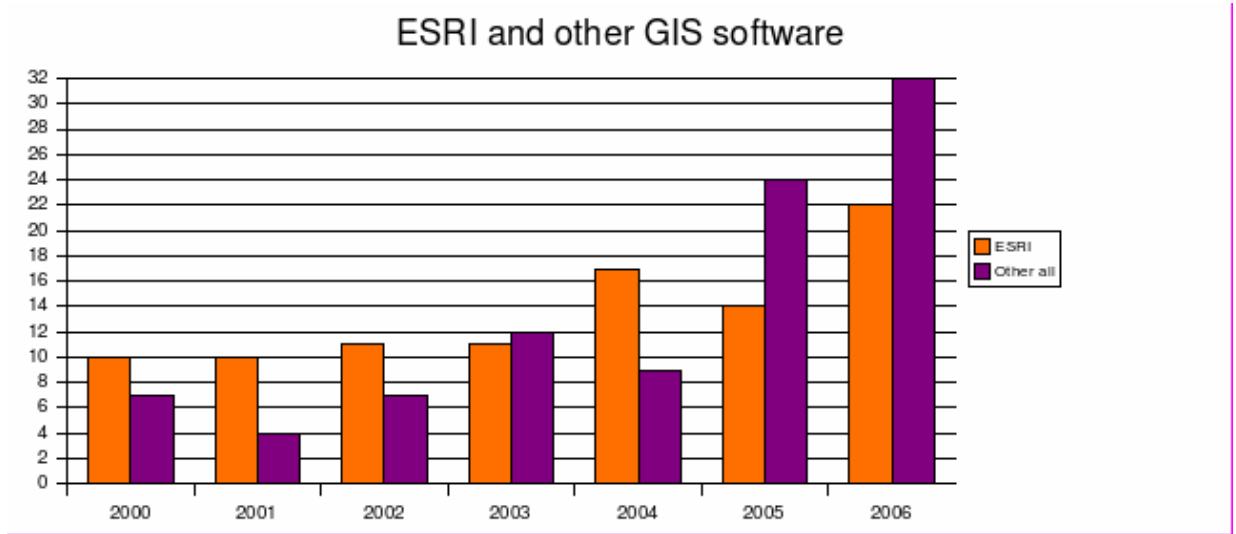

Figure 7: ESRI and other GIS and CAD software

\section{DBMS software}

Students during the 2000 - 2006 period used following DBMS (DataBase Management Systems) software: Oracle, MS Access, MS Excel, MySQL, eXist, PostgreSQL, MS SQL Server (free edition). MS Access and MS Excel are not exactly the DBMS, but they are generally used for data storage and manipulation.

MS Access that was mentioned 31 times (generally more than $80 \%$ of fee DBMS) during whole period. This software is used for teaching in database systems subject. PostgreSQL was mentioned only in a connection to PostGIS software. MySQL was mentioned mainly in a connection with Web Mapping software.

\section{Other software}

Students during the 2000 - 2006 period used following other software: Statgraphics, SPSS, TRANSCAT, Jízní řády, Malování, HYDROG, DOK, HEC-HMS, AEOLIUS, WebCastle, CASC2D, MODFLOW, LiveCD, JGAP, PHPGraph, GIPSY OASIS, Sarovar, GIMP, VirtualDub, Apache, Plone, Zope, Axis, Tomcat, JBOSS.

This is probably quite common that users of the open source software mention any software 


\section{GIS and CAD software 2000 - 2006}

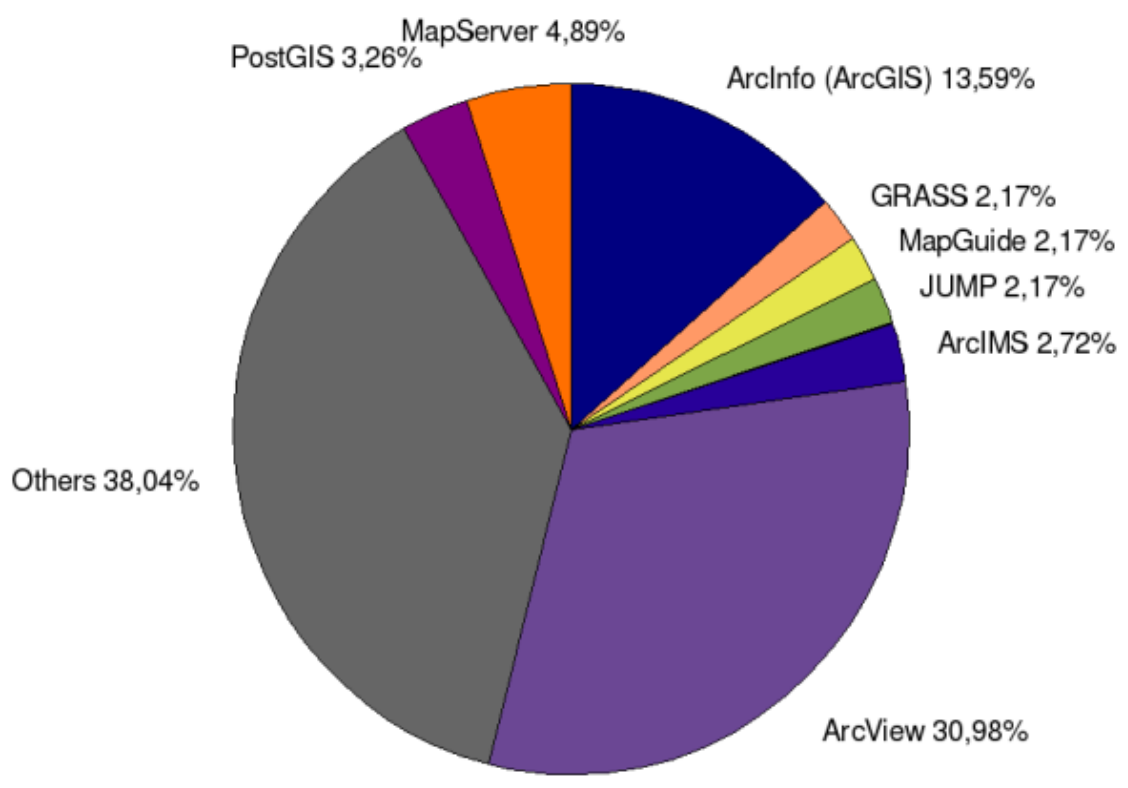

Figure 8: GIS and CAD software 2000 - 2006

\section{GIS and CAD software 2006}

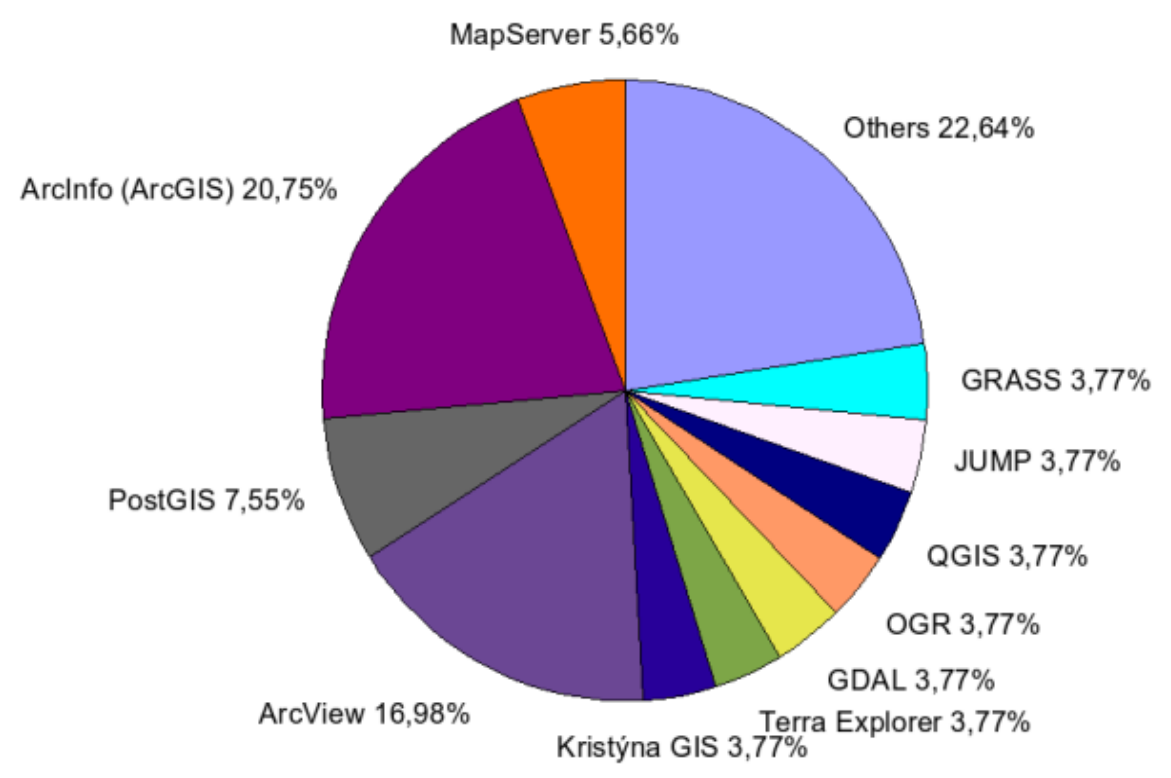

Figure 9: GIS and CAD software 2006

that they used. They usually mean this as an acknowledgements to open source software developers. Users of the commercial software thank by payment. Other software is mentioned 


\section{DBMS software}

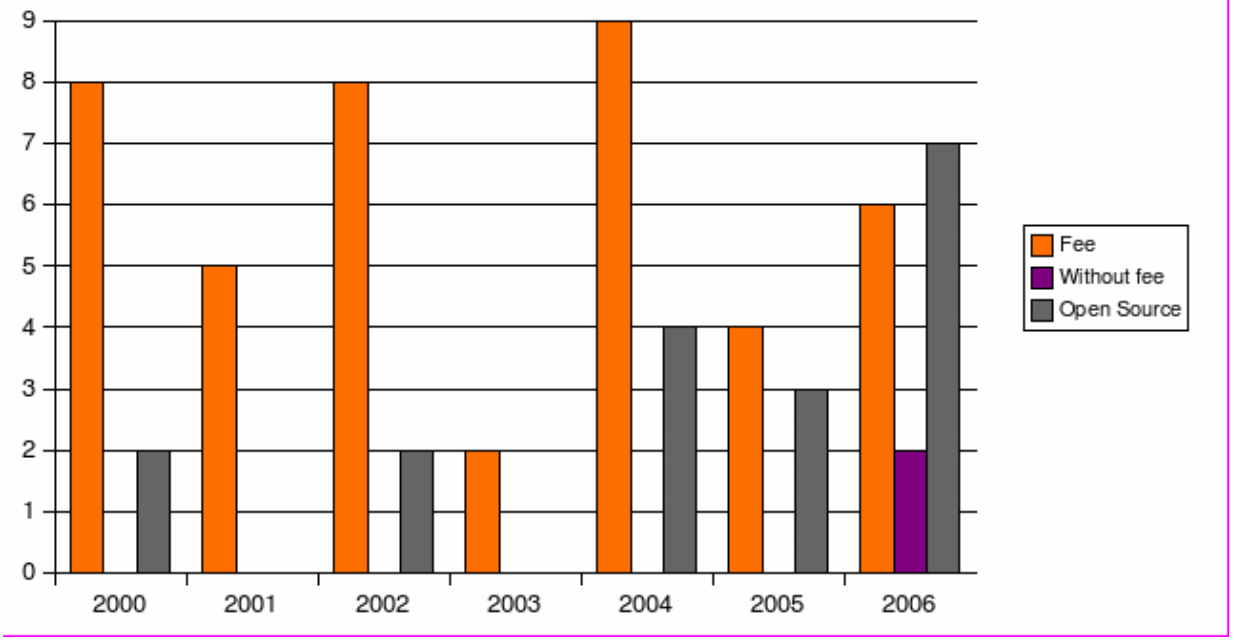

Figure 10: DBMS software

\section{Other software}

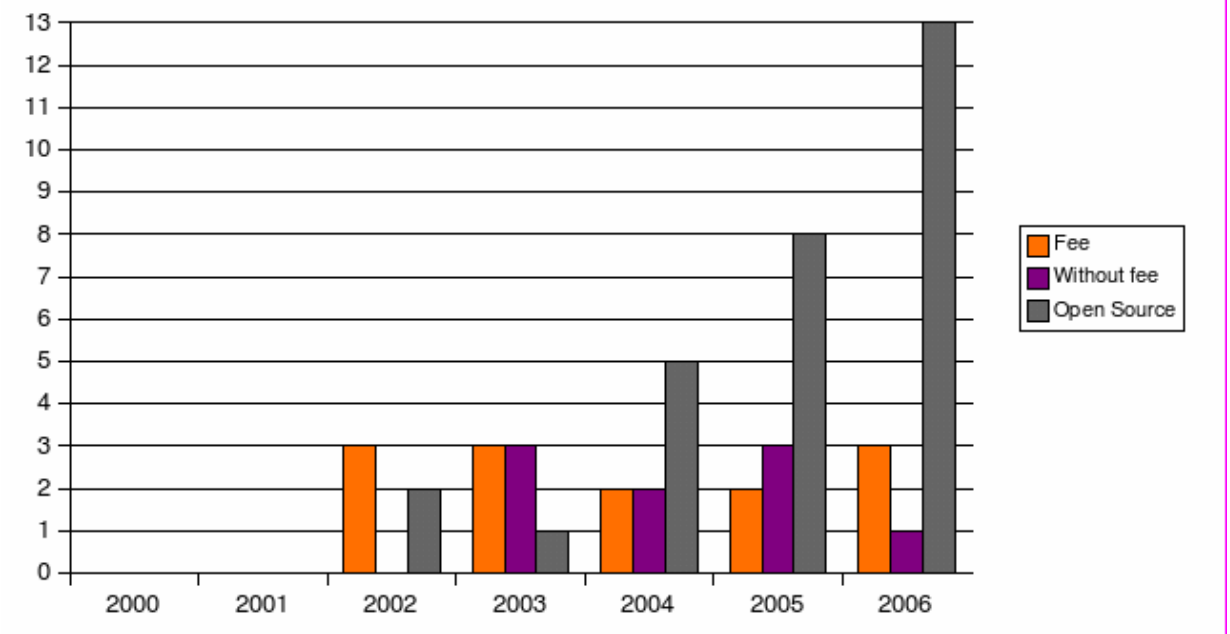

Figure 11: Other software

mainly in the last years, this can be cause of better preciseness of the participants.

\section{Operating systems}

Very interesting is usage of operating systems. There are only a few students that were completely satisfied with GNU/Linux (UNIX - there was used only one UNIX system named Irix) OS only. Most common are students satisfied with OS MS Windows only, but in a last years is quite common combining OS MS Windows with OS Linux. 


\section{Operating systems}

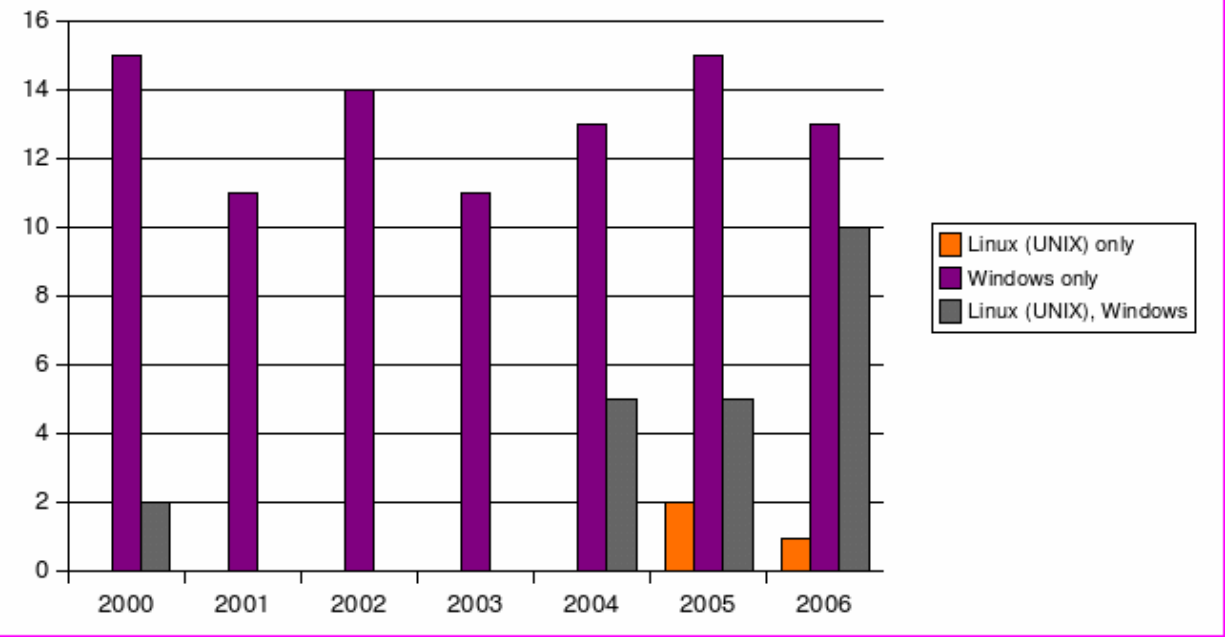

Figure 12: Operating systems

\section{All software}

There are prepared figures 13, 14 and 15 for complete view on the statistics.

\section{All software (without OS)}

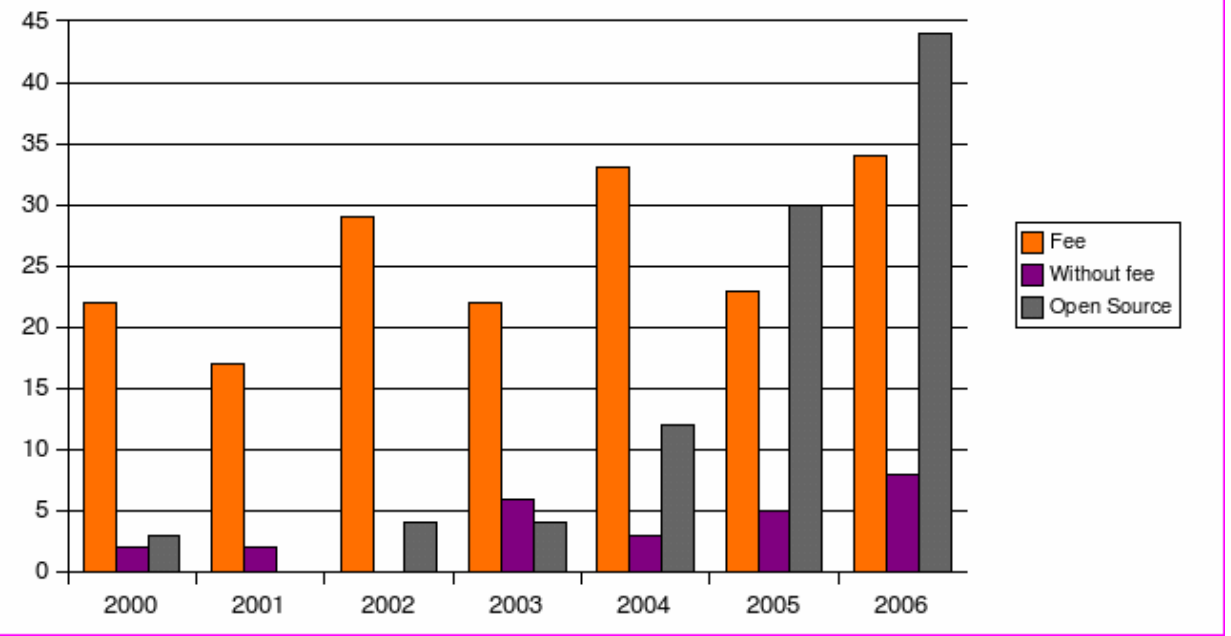

Figure 13: All software (without operating systems)

\section{Programming languages}

Students mentioned programming languages used for their diploma thesis. There are not so big surprises at the following figure. Students can learn PHP, Java and Visual Basic during the study. Usage of the Avenue language is only a reflection of ArcView usage. VRML was (maybe still is) favorite modeling language of the former head of the Institute of Geoinformatics. 


\section{All software by individual student}

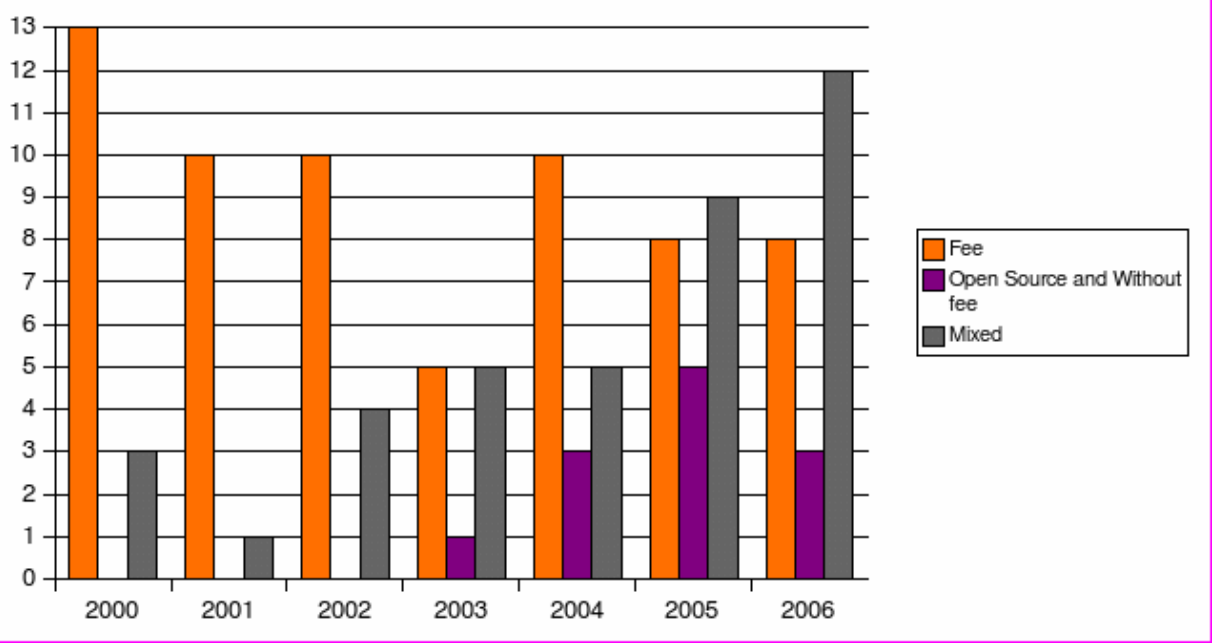

Figure 14: All software (without OS) by individual student

\section{All software (without OS) 2000 - 2006}

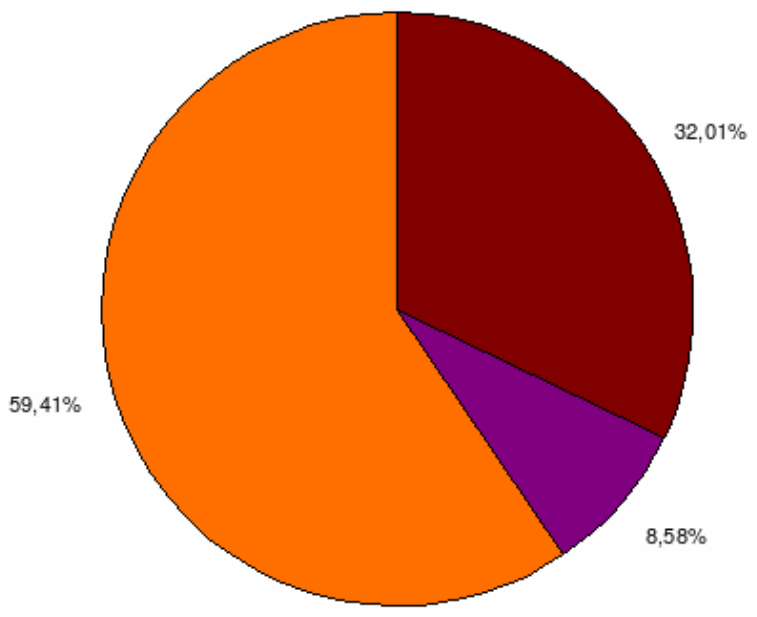

Figure 15: All software (without OS) 2000 - 2006

\section{Few words at the end}

The statistic prepared for this paper is not representative, but shows some trends. Students did not mention all software that they used for their diploma thesis and some of them did not mention any software. For the paper were checked 129 papers form students' conference, 122 students did mention any software. This is the best that we can have for our statistics. We can read all thesis to get better statistic, but this will not be probably efficient. I can make a mistake and did not found all software mentioned during the statistics preparation, but I 


\section{Programming languages 2000 - 2006}

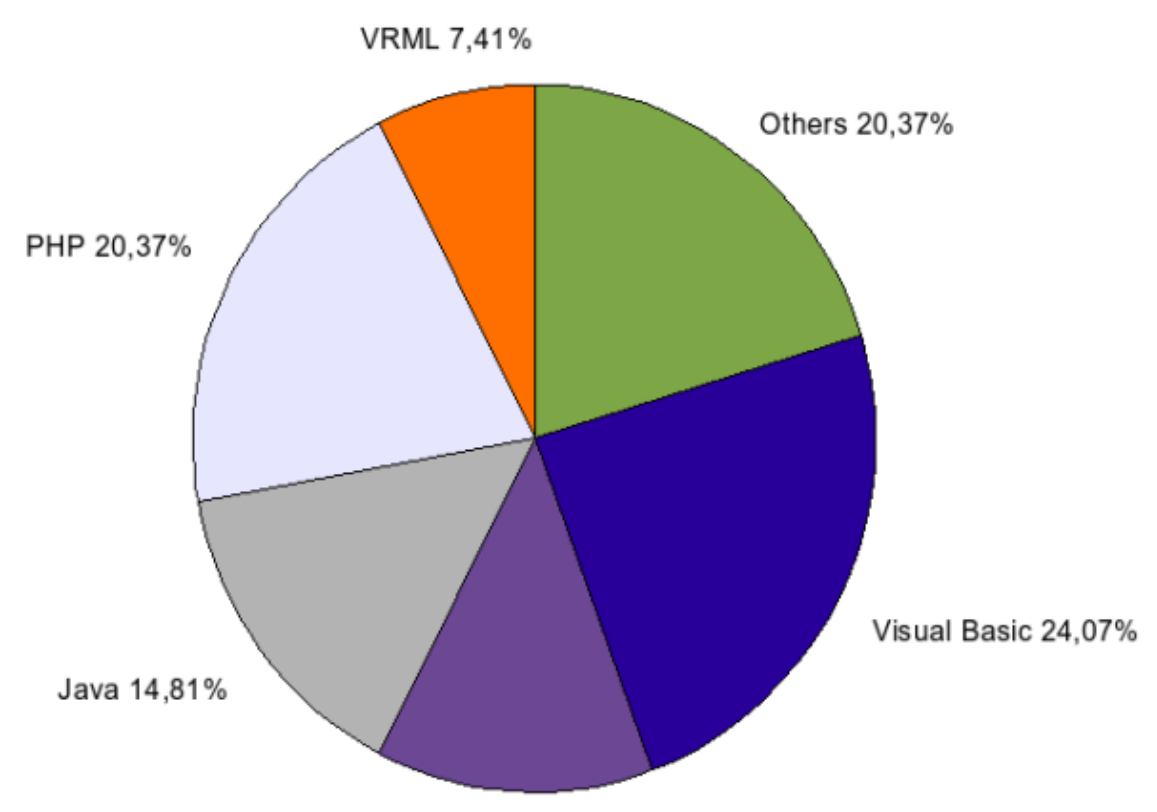

Avenue $12,96 \%$

Figure 16: Programming languages $2000-2006$

believe that I got at least $95 \%$ of mentioned software. 